\title{
Correction to: Methane and Electricity Production from Poultry Litter Digestion in the Amazon Region of Brazil: A Large-Scale Study
}

\author{
Marcelo Mendes Pedroza ${ }^{1}$ (D) Wanderson Gomes da Silva ${ }^{2} \cdot$ Luciene Santos de Carvalho $^{3} \cdot$ Alice Rocha de Souza $^{1}$. \\ Girlene Figueiredo Maciel $^{2}$
}

Published online: 22 April 2021

(c) Springer Nature B.V. 2021

\section{Correction to: Waste and Biomass Valorization https://doi.org/10.1007/s12649-021-01360-x}

The article "Methane and Electricity Production from Poultry Litter Digestion in the Amazon Region of Brazil: A Large Scale Study “ written by Marcelo Mendes Pedroza1 . Wanderson Gomes da Silva2 · Luciene Santos de Carvalho3 - Alice Rocha de Souza1 · Girlene Figueiredo Maciel was originally published online on 7 February 2021 with Open Access under a Creative Commons Attribution 4.0 International License, With the author's/authors' decision to cancel Open Access the copyright of the article changed on 16 April 2021 to (C) Springer Nature B.V. 2021 with all rights reserved.
The original article is corrected.

Publisher's Note Springer Nature remains neutral with regard to jurisdictional claims in published maps and institutional affiliations.

The original article can be found online at https://doi.org/10.1007/ s12649-021-01360-x.

Marcelo Mendes Pedroza

mendes@ifto.edu.br

1 Department of Electrical Engineering, Federal Institute of Tocantins (IFTO), Palmas, Brazil

2 Department of Environmental Engineering, Federal University of Tocantins (UFT), Palmas, Brazil

3 Institute of Chemistry, Federal University of Rio Grande do Norte (UFRN), Natal, Brazil 